\title{
NOISE POLLUTION ANALYSES IN URBAN CITES: BATNA CITY CASE
}

\author{
Haddad Louiza ${ }^{1}$, Haddad Djamel ${ }^{2}$, Aouachria Zéroual ${ }^{3}$ \\ ${ }^{1}$ Laboratory of Natural Risks and Regional Planning, University of Batna, Algeria \\ ${ }^{2}$ Hygiene and Security Institute, University of Batna, Algeria \\ ${ }^{3}$ Laboratory of Applied Physics Energetic, University of Batna, Algeria
}

Received 28 July 2016; accepted 29 August 2016

\begin{abstract}
Urbanization is one of the major events of the contemporary world view to grow with a faster pace. Today there are more than 3 billion urban dwellers and by 2030, it could be three quarters of the population, i.e. $80 \%$ of the world population will live in urban cities. The accelerated urbanization causes an increased need for transport. Although transport has produced beneficial effects for society, but its development also generates negative environmental impacts. Politics, "all to the car" caused problems such as disturbance due to noise. Our study of this phenomenon was based on measurements on site to try to map the noise dominates a study covering most of the urban area of the city of Batna.
\end{abstract}

Keywords: transport, urban environment, noise, noise mapping, pollution.

\section{Introduction}

Silence is a precious good. It is however no longer available anywhere and at any time. The man through its activities pollutes more the environment with noise. The resource, what silence is scarce. Hence it is particularly worthy of protection. Urbanization is one of the major events of the contemporary world view its progress with a rhythm that tends to accelerate. Today there are more than 3 billion urban dwellers and by 2030, it could be three quarters of the population, i.e. $80 \%$ of the world population will live in urban cities (Rogers and Gumuchdjian, 2000). The environmental overload; it is by this Expression that we can characterize these very wealthy environments and artificial where green spaces are reduced and dominated verticality. Indeed the great city would be given the strength and diversity of stimulus and information, especially a source of nuisance for residents. Metropolis broadcasts a stream of messages, be it noise, light or shows (Paulet, 2000; Mérenne, 2003). The problem is the adaptation of the inhabitants at this mass of information that must be ceaselessly to sort. Parry and Small $(2002 ; 2005)$ estimate at 2.0 cents per mile cost of damage done to the environment by a passenger/vehicle in an urban area. The accelerated urbanization causes an increased need for mobility in connection with the expansion of trade and improving the accessibility of various locations, which then causes the swelling of traffic. Although transport has produced beneficial effects for society, but also its development has a negative impact on the environment. Politics "all to the car" caused problems such as:

\footnotetext{
${ }^{3}$ Corresponding author: z.aouachria@univ-batna.dz
} 
i. The spectacular growth of fuel consumption hence the very strong increase in urban pollution,

ii. Traffic congestion in some areas and at certain times,

iii. The increasing number of accidents.

The balance sheets of major transport projects have shown these positive effects do indeed appear that where there are potential: this is not always the place that you hoped because better advantage is sometimes drawn elsewhere of the service offered (Domergue, 2000). A new transport service does not necessarily imply creation of local value added. It may even occur in some cases, a desertification effect by "pumping" of an area that did not know how to grow its new geographic situation by a more dynamic area. Beyond the positive impacts generated by transport on the economy, however, there are very significant negative effects that far from being supported by the economic sphere are left to the community as a whole load: Integration environmental and health aspects into transport policies is essential for achieving sustainable development goals. Thus, the transport will focus mainly in those communities and its impact will therefore appear very significantly on human health, marine mammals (Richardson et al., 1995), the environment and even will drive to climate variations. Climatic conditions and the phenomenon of urbanization (urban transport) have adverse effects directly on the society through more intense heat waves that can give rise to what has been called the urban heat island causing microclimates and sound waves representing one of the urban transport nuisances or noises produced by wind turbines installed on the roofs as shown in Fig. 1b (Smith, 2010; Safina and Chasis, 2004; Aouachria and Haddad, 2010).

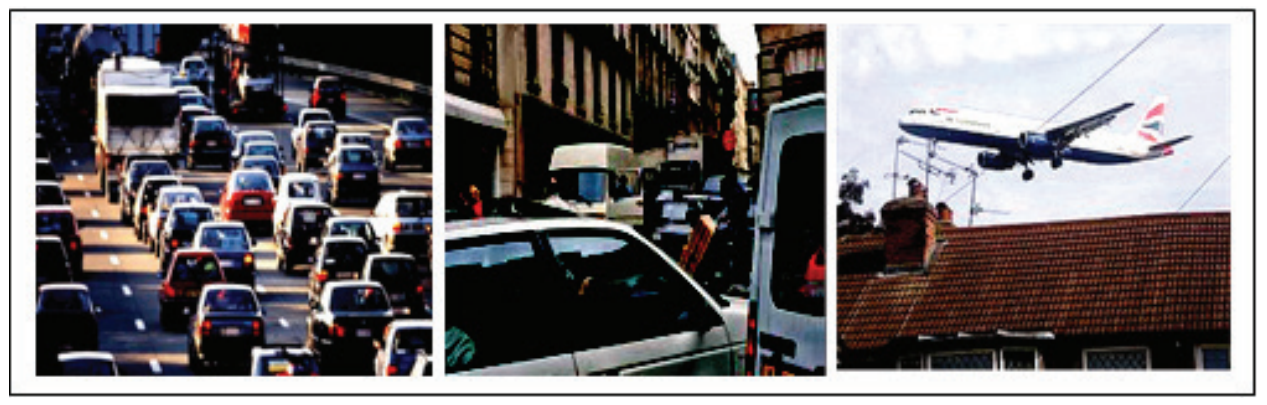

(a)

(b)

Fig. 1.

Generation of the Noise by Transport Systems

To act and reduce or even eliminate a phenomenon, we need to measure and evaluate. Regarding noise, the evaluation method is difficult to implement for assessing the impact for residents, competing transport infrastructure in each project. Indeed, it requires enumerating the residents, who are subject to different noise levels (Meyronneinc, 1998). Nuisances that affect the environment are many and various. They are pretty well marked and have resulted in many respective impact indicators (Maurin, 2007). The undergone noise is a source of stress and deteriorating 
health. This is one of the first sources of complaints of the inhabitants; whether it is in urban or industrial area. To fight against this nuisance, we must know: its sources intensity and nature of the noise, and exposure to it. To develop more effective strategies, various systems and noise mapping models appeared. By the late 1990s, and more and more often it is the first large urban agglomerations and large manufacturers that have mapped the noise ratio for:

i. better control in order to enhance the quality of life or safety and health;

ii. to communicate on common bases and spatially with the locals and noise sources actors;

iii. for environmental reasons, it is need to limit disturbance to wildlife. This is one of the elements to be considered in the mapping of biological corridors;

iv. for Environmental Studies of a road project prior to impact public inquiries and studies;

v. for environmental observatories and size and position the acoustic screens.

It is this approach that we will apply in studying the impact of noise caused by urban transport in the city of Batna where we will collect measurements of the intensity of the noise level meter on its main roads.

\section{Method and Materials}

Before starting our study, we will present some concepts and information about the physics of sound.

\subsection{Generating Problem}

If we limit the environmental problems related to transport excluding economics, the feedback tool design has become very complex because environmental issues are becoming globalized more and more. Also transport have multiple and varied impacts. A vehicle routing planning system for goods distribution in urban areas was tested for urban goods distribution in Sofia, Bulgaria using Google maps and genetic algorithm (Berov, 2016).

Data collected to estimate all these nuisances are heterogeneous in nature (gas concentration, noise level, discomfort felt death toll, etc.). It is desired to use different time scales (hour, day, year, etc.) and space (neighbourhood, city, region etc.) to analyze such an environmental situation. The environmental acoustics is concerned with noise. In order that we can determine this sound harmfulness's to human health and to modify the production and transmission of own noise, we must opt for a physical analysis of the phenomenon. The acoustic point of view, noise is unwanted sound. The realization of transport infrastructure is at the junction of public economic calculation that can be described as "substantial" because it can decide on the merits of the assessment of the socioeconomic profitability of a project and an administrative law having a "procedural" logical nature. Neither substantial economic calculation, nor a procedural administrative law are able to establish a criterion and fair assessment tools address the nuisance of transport infrastructure. However, a Republican justice is the principle of the equality of citizens before public burdens. The question that we can ask is that while the means to ensure this equality, which would require all residents of infrastructure, is treated uniformly (Thierry and Nadine, 2008). 


\subsection{Noise Analysis of the Phenomenon}

Acoustics is the science of sound, including its production, control, transmission, receipt and its effects. Hearing details the physiology of the ear (external, middle and inner ear) and explains the mechanisms of perception of sound by the ear, while psychoacoustic studies how sounds picked up by the auditory system are interpreted by the brain human. The sound is generated by several mechanisms and is always associated with fluctuations of small scale and speed that produces pressure sensations in the human ear. They are characterized by their wavelength, $\lambda$, frequency $f$, and their speed, $u$, which is defined by Eq. (1):

$u=f \lambda$
The wind speed is a function of the environment where it spreads. The sound becomes noise when it is not desirable. There are many physical parameters that have been defined and cannot compare, classify, and also provide information on the human perception of sound (Wagner et al., 1996; Maurin, 2003). The environmental noise is concerned about reducing noise pollution. For starters, it should measure. The instruments necessary to achieve these measures are called sound level meters, Fig. 2 . A sound level meter is an instrument designed to measure the sound pressure level is a physical magnitude related to volume. It is used in noise pollution studies and environmental acoustics to quantify noise and noise pollution, mostly industrial noise and road, rail and air transport.

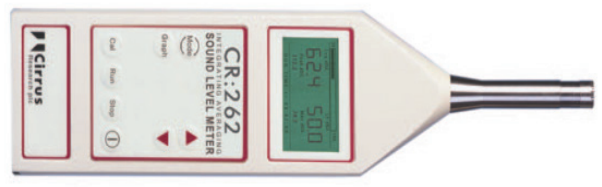

Fig. 2.

Type of Meter Used in Our Study

One can use two sizes, linked together, to express the noise: the sound intensity in watts per square meter, and the sound pressure in Pascal's. The measurement of the sound pressure is carried out in a given point. Note that it is inconvenient to represent sound pressure values in Pascal's spread on a scale of one to a million, the weakest to the strongest sounds, much less to represent the intensity, spread over a wide one to one thousand billion since the sensitivity of the ear is relative, that is to say an increase in the sound pressure of $1 \mathrm{~Pa}$ to $1.5 \mathrm{~Pa}$ is perceived as being identical to an increase of $0.1 \mathrm{~Pa}$ 0.15 . What matters is the Multiplier (in both cases, 50\%). However, it rarely uses these physical units in everyday communication. It is more desirable to present the sound pressure and intensity by a dimensionless quantity called decibels (dB). A Bel is the logarithm of the power ratio between a characteristic value of its study and that of 
a reference tone. These reference values for the acoustic intensity, $\mathrm{W}_{0}=1 \times 10-12 \mathrm{~W} \cdot \mathrm{m}^{-2}$ and for the sound pressure $\mathrm{P}_{0}=2 \times 10-5 \mathrm{~Pa}$ (Filippi, 1998).

It is important to distinguish between the level of pressure and sound power. The sound power level is a property of the sound source and gives the total power emitted by this source. The sound pressure level is a property of its position relative to a given observer and can be measured by a single microphone. In practice, the amplitude of an acoustic quantity is given in logarithmic form expressed in decibels above or below the zero baselines. The sound pressure level in decibels unit is given by Eq. (2) (Ver and Beranek, 2006):

$$
L_{p}=10 \log _{10}\left(\frac{P}{P_{0}}\right)
$$

And the power level in decibels unit is given by Eq. (3):

$L_{W}=10 \log _{10}\left(\frac{W}{W_{0}}\right)$

To predict the sound pressure level at a given distance from the light source of its power, we must examine how sound waves travel. Details on the propagation of these waves are provided by Chignell (1986) with the hypothesis of (Snieder, 1986). In the case of single turbine support, the sound pressure level is calculated, assuming that the propagation is spherical, which means that the level is reduced by $6 \mathrm{~dB}$ when the distance is doubled. A simple model, based on sound propagation along the reflecting hemispherical reflective surface and whose absorption parameter, the sound pressure level is given by Eq. (4):

$L_{p}=L_{W}-10 \log _{10}\left(2 \pi R^{2}\right)-\alpha R$

Where $\alpha=0.005$ is the absorption coefficient $\left(\mathrm{dBm}^{-1}\right), R$ is the distance between the noise-emitting source and the location of the observer.

The relevance of field is limited to intercity traffic areas as well as on urban roads well cleared. In this case, the propagation of noise infrastructure characterized by: $i-$ a roadway width $L$; ii- a $Q_{V L}$ and $Q_{P L}$ rate; iii- an average speed of flow, $V$; iv- at a distance $x$ dwellings; $\mathrm{v}$ - for an infrastructure seen at an angle of $\theta$, is written, (SESP/MTETM, 2006):

$L A_{e q}=18+10 \log \left(Q_{V L}+E \cdot Q_{P L}\right)+20 \log (V)-12 \log \left(x+\frac{L}{3}\right)+10 \log \left(\frac{\theta}{180}\right)$

Where, $E$ is the acoustic equivalent VL/ $P L$. This equation is modified to take into account the linear attenuation (Eq. (4)) due to absorption by the air that transforms a part of the sound energy into heat. This term depends on the frequency of sound, temperature and air humidity. A value of $4 \mathrm{~dB}(\mathrm{~A})$ per $\mathrm{km}$ has been retained (SESP/ MTETM, 2006).

\subsection{Presentation of the Study Area}

Our study was performed on a site that is at the centre of the wilaya of Batna northeast of the country. It represents the centre of Batna, capital of the wilaya (Fig. 3). 


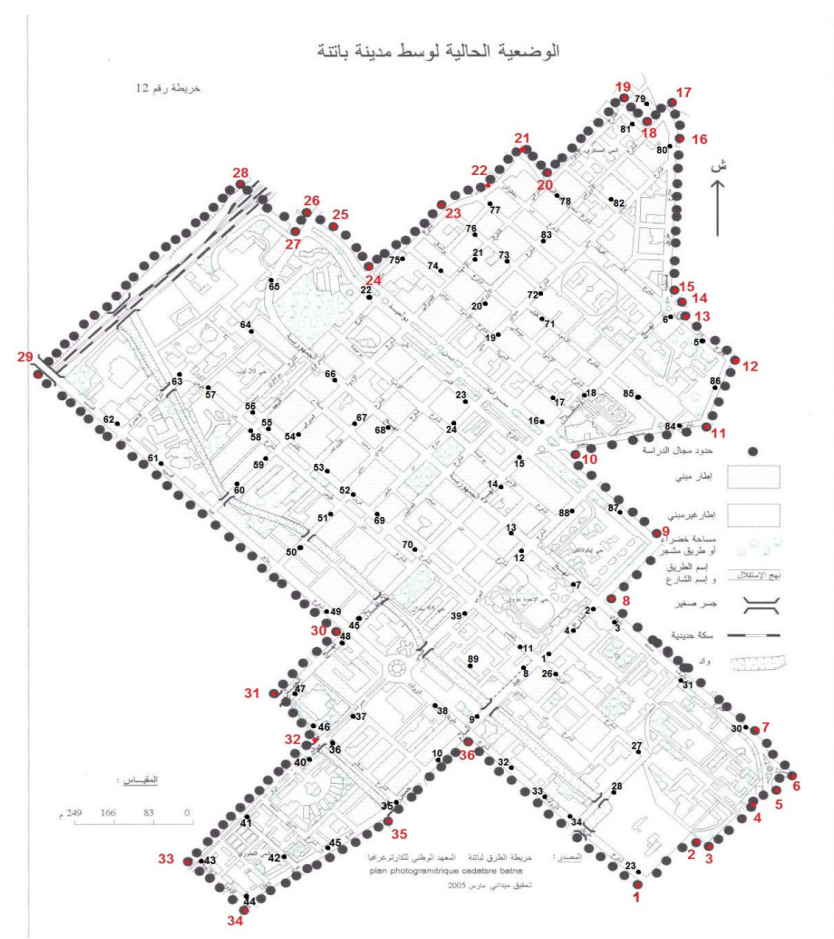

Fig. 3.

Boundary of the Study Area

Source: Photographic Plan, Cadastre of Batna. Field Investigation, March 2005

\section{Methodology}

Any study is characterized by:

i. A definable management and regularly followed in an operation of the mind,

ii. A program setting a series of operations to be performed,

iii. Indicating some mistakes to avoid.

Thus, inspiring them a methodological approach, implemented for the development of strategic noise maps, which consists of different steps that schematic on Fig. 4. In this study we focused on data from road transport in the central city of Batna.

\subsection{Measuring Instrument}

\subsubsection{Technical Data}

The sound level meter is the most common instrument for measuring sound levels. The simplest meter consists of a microphone, a frequency weighting filter, an energy level converter (RMS) and a logarithmic display. The most advanced sound level meters incorporate standardized filter strips octave or octave band fractions, and provide additional measurement and analysis capabilities (Langlois and Rousset, 2015). The sound level meter used in our study, Fig. 2 , has the following characteristics: 
- $\quad$ Measuring ranges: $\mathrm{L}: 32 \mathrm{~dB} \sim 80 \mathrm{~dB}, \mathrm{Md}$ : $50 \mathrm{~dB} \sim 100 \mathrm{~dB}, \mathrm{H}: 80 \mathrm{~dB} \sim 130 \mathrm{~dB}$

- Accuracy: + / - $1.5 \mathrm{~dB}$ (with reference range) and Resolution: $0.1 \mathrm{~dB}$

- Reference Sound Level \& frequency: $94 \mathrm{~dB}, 1 \mathrm{k} \mathrm{Hz}$

- Sensor indicator Features: Fast: 125 ms Slow: $1 \mathrm{~s}$

- Analogical output signal: AC 1Vrms for each range

- Dimensions: 235 (L) x $58.4(\mathrm{~W}) \times 34$ (H) $\mathrm{mm}$

- Weight (approx.): 220g (includes batteries)

- Power Source: 9V (6F22.006P) x 1 Battery
It is also possible to reproduce by simple frequency weightings, the combined effects of different frequencies that can be perceived as noise with this type of sound level meter.

To represent this weighting, the decibel symbol is accompanied by a suffix A, which follows the abbreviation $\mathrm{dB}$ ( $\mathrm{dBA}$ ), means the frequency response function that filters the sounds picked up by the sound level meter microphone. In any assessment of the noise, it is important that the receiving points are clearly defined and that their contact information as is recorded in Table 1.

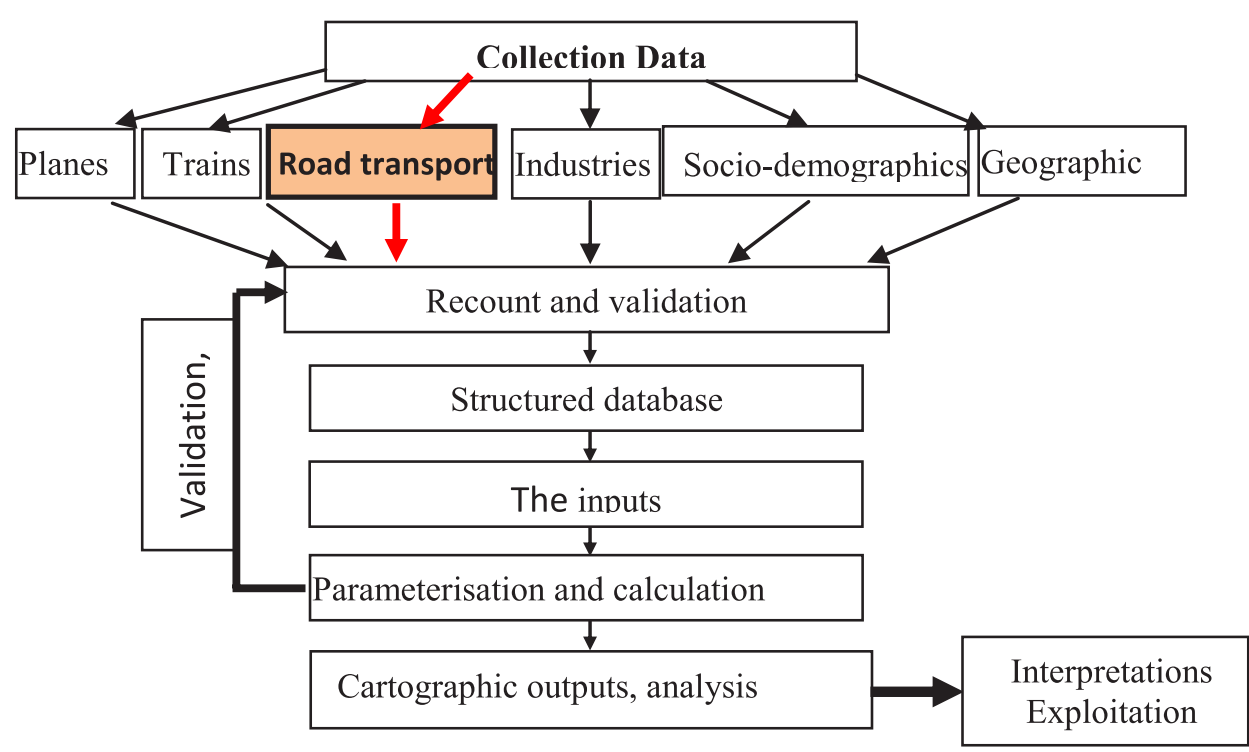

Fig. 4.

Strategic Noise Mapping in the Environment

Source: Boutin and Paquereau (2011) 


\section{Table 1}

Results of Measurements of Noise Intensity in $d B(A)$ Different Points on the Site

\begin{tabular}{|c|c|c|c|c|c|c|c|}
\hline Pts & dBA & Pts & dBA & Pts & dBA & Pts & dBA \\
\hline & Max & & Max & & Max & & Max \\
\hline 1 & 649 & 23 & 64.6 & 45 & 74.8 & 67 & 527 \\
\hline 2 & 61.0 & 24 & 52.7 & 46 & 69.5 & 68 & 49.7 \\
\hline 3 & 64.5 & 25 & 67.1 & 47 & 76.6 & 69 & 65.8 \\
\hline 4 & 68.6 & 26 & 49.1 & $\frac{T}{48}$ & 76.4 & 70 & 67.3 \\
\hline 5 & 64.7 & 27 & 52. & 49 & 66.9 & 71 & 54.8 \\
\hline 6 & 68.8 & 28 & 57.1 & 50 & 47.4 & 72 & 44.3 \\
\hline 7 & 64.9 & 29 & 63.0 & 51 & 54.1 & 73 & 60.4 \\
\hline 8 & 67.0 & 30 & 63.6 & 52 & 64.8 & 74 & 49.9 \\
\hline 9 & 69.0 & 31 & 61.7 & 53 & 65.1 & 75 & 51.6 \\
\hline 10 & 47.6 & 32 & 62.3 & 54 & 64.0 & 76 & 49.1 \\
\hline 11 & 66.4 & 33 & 60.0 & 55 & 64.0 & 77 & 51.8 \\
\hline 12 & 67.1 & 34 & 61.0 & 56 & 50.0 & 78 & 43.0 \\
\hline 13 & 61.1 & 35 & 66.0 & 57 & 65.7 & 76 & 49.1 \\
\hline 14 & 63.3 & 36 & 62.6 & 58 & 66.7 & 80 & 53.2 \\
\hline 15 & 64.6 & 37 & 56.8 & 59 & 50.2 & 81 & 55.6 \\
\hline 16 & 63.1 & 38 & 57.6 & 60 & 56.1 & 82 & 54.2 \\
\hline 17 & 59.5 & 39 & 64.6 & 61 & 65.2 & 83 & 66.6 \\
\hline 18 & 66.9 & 40 & 65.3 & 62 & 64.5 & 84 & 52.7 \\
\hline 19 & 57.0 & 41 & 66.7 & 63 & 48.9 & 85 & 43.7 \\
\hline 20 & 54.7 & 42 & 49.2 & 64 & 51.0 & 86 & 51.7 \\
\hline 21 & 52.4 & 43 & 67.2 & 65 & 64.9 & 87 & 55.1 \\
\hline 22 & 66.9 & 44 & 68.0 & 66 & 53.3 & 88 & 65.5 \\
\hline
\end{tabular}

\subsubsection{Calibration}

A sound level meter must be calibrated before every measurement with a standard source. To the end of each series, the calibration must be checked and the correction should be noted. If this correction is greater than 0.5 $\mathrm{dB}$, sound records are invalidated. Precision sound level meter and standard source should be checked once a year by a laboratory with the necessary accreditation.

\subsection{Measures and Treatments}

\subsubsection{Treatment by GIS}

The measurements were processed using a geographic information system (GIS) that allowed us to develop a noise map. The area of study is in the centre of the city of Batna. The positions of measurement points are selected in the vicinity of noise sensitive structures such as schools, clinics and hospitals, and buildings whose coordinates are defined and carried in Table 1 . The meter is placed each point to the height of $70 \mathrm{~cm}$ from the ground (corresponding to the seating position of a person). The sound level meter simultaneously indicating two noise levels ( $\max$ and $\mathrm{min}$ ), is left 7 minutes to reach the stability of the value before it is registered. The required values of the noise intensity are systematically recorded on 88 measurement points are also shown in Table 1. The choice of these measurement points is guided by the results of the counting of a questionnaire conducted on the nuisance of transport origin evoked by people complaints.

\subsubsection{Numerical Simulation}

As the geometry of the study domain is complex, we chose the mesh generator, Gambit, for its discretisation and we use a polynomial interpolation method with the least squares method. The mesh oh the study area is presented in Fig. 5. 


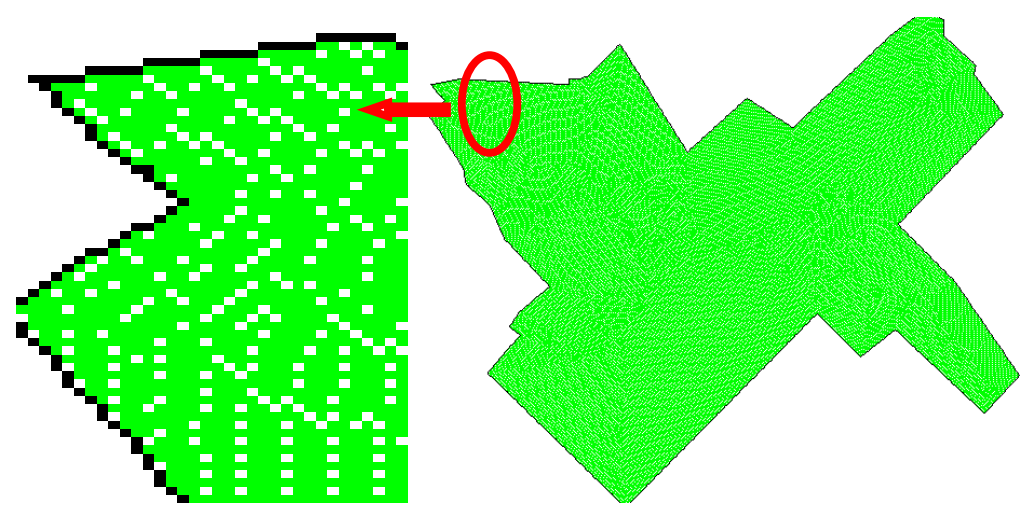

Fig. 5.

Mesh of the Study Area

The mathematical formulation consider a polynomial equation of two variables representing the coordinates points of measure and the value of function denotes the intensity of the noise at this point. So we can represent this by Eq. (6):

$$
P(x, y)=c_{1}+c_{2} x^{l}+c_{3} y^{1}+c_{4} x^{2}+c_{5} x y+c_{6} y^{2}+\ldots .+c_{20} x^{5}+c_{21} y^{5}
$$

Then calculating the coefficients $C_{i}$ of the polynomial in two variables and $5^{\text {th }}$ degree is needed. This interpolation allows us to determine the noise intensity values in each node of the mesh area of study. For doing this, transform the problem in matrix equation:

$A C=I$

Which takes the form below and the calculation is done using a program developed in FORTRAN language.

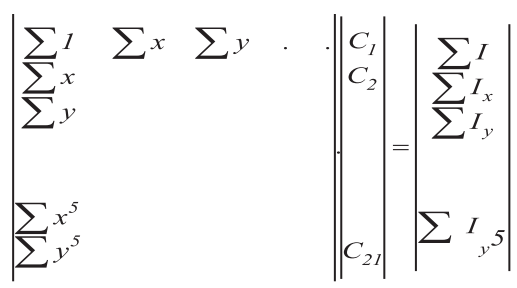

\section{Results and Discussions}

Noise maps are strategic documents across large territories. They aim to give a macroscopic representation of the noise exposure of populations, vis-à-vis road transport infrastructure noise was determined from road transport on the basis of a system of geographic information (GIS) analyze the situation in terms of noise. Our investigation leads to the results those we have present as a sound map on the Fig. 6 . This map represents the sound levels related to road transport urban infrastructure. Cartography, presented to the colour scale as iso-contours, highlighted the areas affected by the sound pursuant to noise classification of road transport infrastructure. The assessment of noise exposure of populations and sensitive institutions is carried out by the maximum sound level measured in front of the building to $70 \mathrm{~cm}$ in height above natural land, $1.5 \mathrm{~m}$ in front of the facades and without taking into account the latest reflection of noise on the facade. They are of more than $40 \%$ of the studied area is subject to sound effects whose intensity is localized between $60-76.6 \mathrm{~dB}$ represents the threshold for noise. The map shows that most of this space is 
located south of the city. This part of the area is characterized by the convergence of the road network and concentration educational institutions in particular university and business activities. This puts the sector in chronic exposure to excessive noise which is one of the biggest environmental problems viewpoints of the health and the economy. It is characterized by very intense flow of urban traffic, which generates noise.

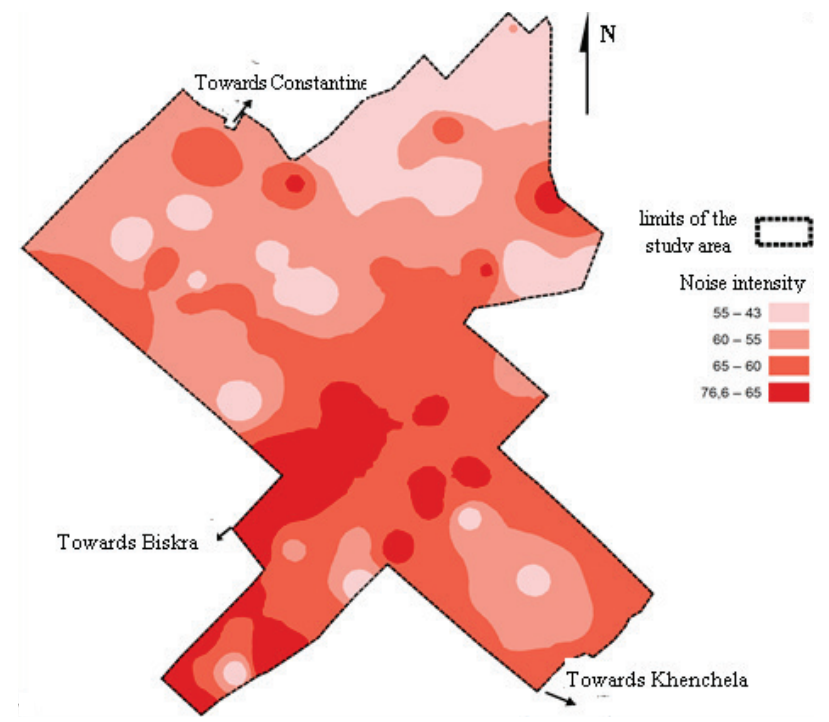

Fig. 6.

Noise Mapping

\section{Conclusion}

Chronic exposure to excessive noise is one of the biggest environmental problems of the views of the health and the economy. The noise is almost ubiquitous in our daily lives. Faced with these growing nuisance noises, several solutions are implemented at different levels. We identify responses by policy and decision makers in the administration (legal and regulatory responses). We also find solutions planning and land use. We also note that technical solutions have been developed to improve the acoustic performance of the products (quieter products, sound insulation, protection products). We also identify educational and artistic responses awareness and alert. To facilitate traffic and especially reduce the generated noise must be taken on the urban plan and spatial planning, the following measures:

- Apply the principles of prevention as part of the planning: reconversion of the most exposed areas, implementation of activities along roads to protect residential areas, etc.

- Consider constructive measures of protection: wall, mound.

- Establish and implement remediation program roads where noise levels are exceeded.

- Develop a traffic simulation model loaded and determine the temporal 
evolution of the flow of vehicles to allow a finer estimation of nuisance at intersections, network components where speed fluctuations, acceleration and direction are the most sensitive.

Perspective to pursue this objective, further study attempts to define, consistent with the desired accuracy in the representation of acoustic phenomena, the factors to be considered in the model characterizing the behaviour of vehicles and influencing different issues.

\section{References}

Aouachria, Z.; Haddad, L. 2010. Wind Power: Environmental Aspects and Impacts, Renewable Energy Review, (In French: Energie éolienne: Aspects et impacts environnementaux, Revue des Energies Renouvelables), SMEE'10 Bou Ismail Tipaza, 27-36.

Berov, T.D. 2016. A vehicle routing planning system for goods distribution in urban, International Journal for Traffic and Transport Engineering, 6(2): 159-167.

Boutin, C.; Paquereau, S. 2011. Strategic noise mapping in the environment of the Urban Community Grand Poitiers Non Technical Summary. (In French: Cartographiestratégique du bruit dans l'environnement de la Communautéd'Agglomération Grand Poitiers - Résumé non technique).

Chignell, R.J. 1986. Electromagnetic Interference from Wind Energy Conversion Systems - Preliminary Information. In Proceedings of the European Wind Energy Conference, 583-586.

Domergue, P. 2000. Reduce the external effects of transport on the environment, the Supreme Council of rail public service, Mines Annals. General Planning Commission. France. (In French: Réduire les effets externes des transports sur l'environnement, Conseil supérieur du service public ferroviaire, annales des mines. Commissariat général du plan).
Filippi, P. (Ed.) 1998. Acoustics: Basic physics, theory and methods. Academic Press (1994 in French).

Langlois, E.; Rousset, D. 2015. Calibration methods for quantification of pollutant, Pollutants metrology, INRS, France. (Méthodes d'étalonnage pour la quantification des polluants, Métrologie des polluants, INRS, France).

Maurin, M. 2003. Reflections about numerical relationships between transport noise and expressed discomfort, Search Transport Security (In French: Réflexions à propos des relations numériques entre le bruit des transports et la gêne exprimée, Recherche Transports Sécurité), 78: 63-77.

Maurin, M. 2007. Classification for the design and aggregation of environmental impact indicators, Search Transport Security (In French: Pour une classification de la conception et de l'agrégation des indicateurs d'impact sur l'environnement, Recherche Transports Sécurité), 89: 243-266.

Mérenne, E. 2003. Transport geography, constraints and challenges, University Presses of Rennes, (In French: Géographie des transports, contraintes et enjeux, Presses universitaires de Rennes), 239 p.

Meyronneinc, J.P. 1998. Transport copes with the environment (In French: Le transportface à l'environnement), édit. CELSE, Paris.

Parry, I.W.H.; Small, K.A. 2002. Does Britain or the United States Have the Right Gasoline Tax, RFF Discussion Paper 02-12 rev, Resources for the Future, Washington DC.

Parry, I.W.H.; Small, K.A. 2005. Does Britain or the United States Have the Right Gasoline Tax, American Economic Review, 95(4): 1276-1289.

Paulet, J.P. 2000. Urban geography, (In French: Géographie urbaine), Collection U. Geography, Armand Colin/ HER, Paris. 
Richardson, W.J.; Greene, C.R. Jr.; Malme, C.I.; Thomson, D.H. 1995. Marine Mammals and Noise, Academic Press, New York.

Rogers, R.; Gumuchdjian, P. 2000. Cities for a Small Planet (In French: Des Villes pour une petite planète), Moniteur, Paris, 22 p.

Safina, C.; Chasis, S. 2004. Saving the oceans, Issues in Science and Technology, 21(1): 37-44.

SESP/MTETM. 2006. Politique de lutte contre le bruit dans les transports routiers - Les comptes des transports en 2005 (tome 2). Available from Internet: <www.statistiques. developpement-durable.gouv.fr $>$.

Smith, N. 2010. Turn it Down, Scholastic Superscience, 21(6): 6-8.
Snieder, R. 1986. The influence of topography on the propagation and scattering of surface waves, Physics of the Earth and Planetary Interiors, 44: 226-241.

Thierry, K.; Nadine, L. 2008. All equal before the nuisance of transport infrastructure, Economic calculation and administrative law to challenge the fairness Geography, economy, society (In French: Tous égaux face aux nuisances des infrastructures de transport, Le calcul économique et le droit administratif au défi de l'équité Géographie, économie, société), 10: 350-364.

Ver, I.L.; Beranek, L.L.; 2006. Noise and Vibration Control Engineering: Principles and Applications, Hoboken, N.J.: John Wiley \& Sons, $2^{\text {nd }}$ Ed. New York.

Wagner, S.; Bareib, R.; Guidati, G. 1996. Wind Turbine Noise, Springer, Berlin.

\section{jitte 264}

